\title{
Usefulness of the S-O clip in balloon enteroscopy-assisted endoscopic retrograde cholangiopancreatography
}

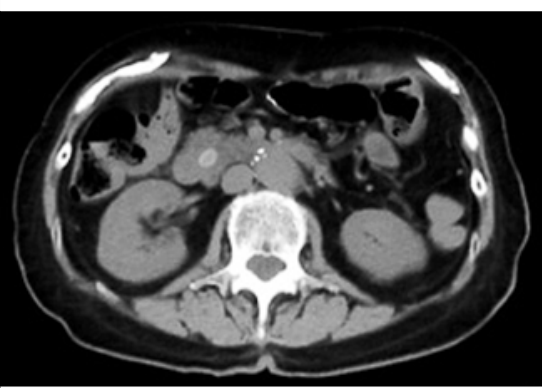

Fig. 1 Computed tomography scan showed a 12-mm biliary stone in the common bile duct.

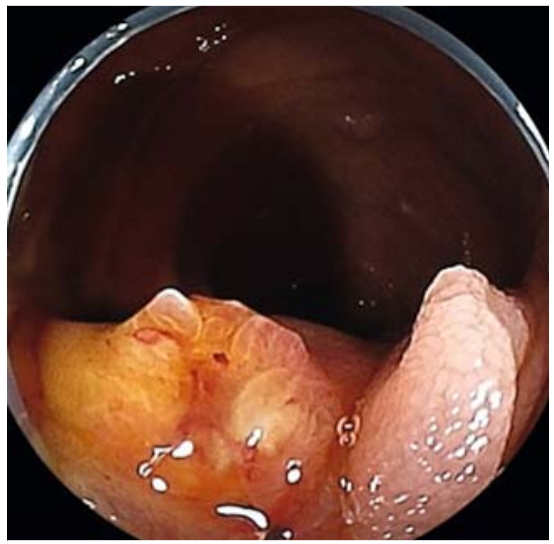

Fig. 2 The orifice of the ampulla was visualized with assistance from S-O clip countertraction.

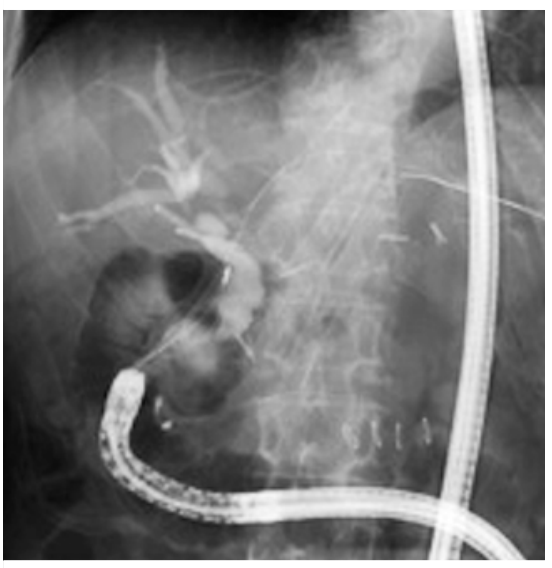

Fig. 3 The papilla was dilated to $13 \mathrm{~mm}$ using a large-balloon dilator, and the stone was removed safely using lithotripsy.

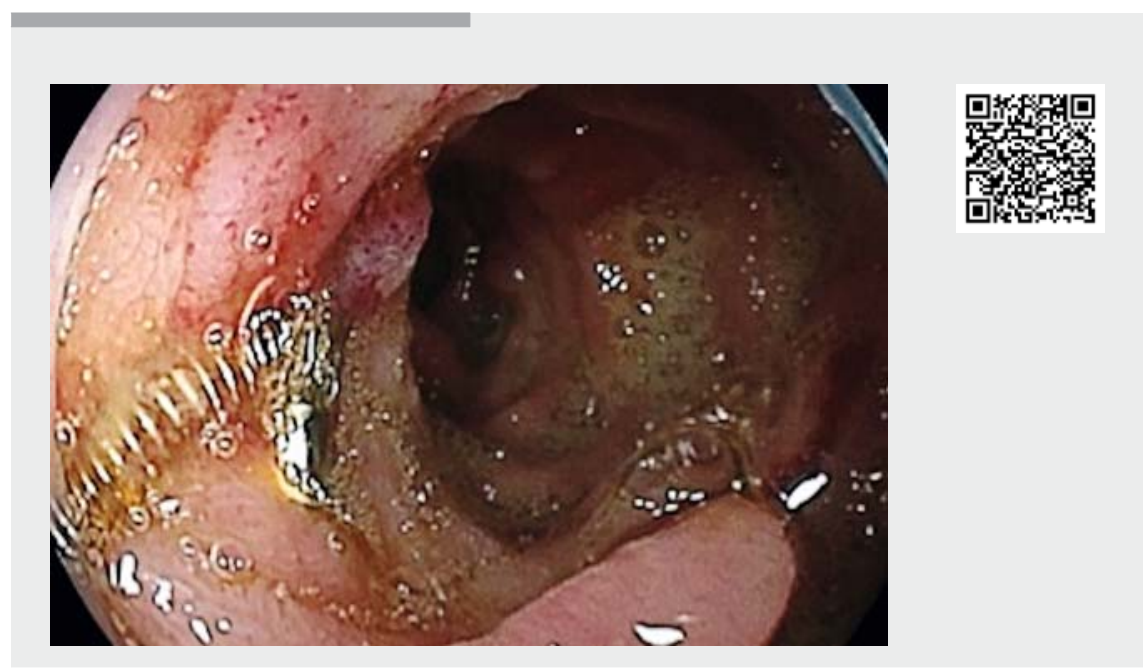

Video 1 The S-O clip was used to position the ampulla to face the instrument. Then, we visualized the orifice of the ampulla and cannulated it to access the bile duct.

A 77-year-old woman with a history of total gastrectomy with Roux-en-Y anastomosis was admitted with acute gallstone cholangitis (> Fig.1). We attempted endoscopic stone removal with a doubleballoon enteroscope (DBE) (EI-580BT; Fujifilm, Osaka, Japan).

A DBE with a transparent hood was inserted, and we successfully approached the ampulla. However, the ampulla faced away from the instrument, owing to a fold and periampullary diverticulum. It was difficult to cannulate the bile duct, despite attempting to reposition the ampulla to face the instrument by holding the fold using the hood. We finally used an S-O clip (Zeon Medical, Tokyo, Japan) [1] to pull the periampullary mucosa and reposition the ampulla to face the instrument.

The S-O clip is a through-the-scope endoscopic clip with a 5-mm-long spring attached to a single 4-mm-diameter nylon loop. Once the S-O clip was deployed to the target, the nylon loop was pulled and attached to the distant mucosa, $5 \mathrm{~cm}$ away from the first S-O clip, using a second conventional endoscopic clip, pro- ducing "countertraction." We visualized the orifice of the ampulla and cannulated it to access the bile duct ( $\mathbf{F i g} . \mathbf{2}$ ). The papilla was dilated to $13 \mathrm{~mm}$ using a large-balloon dilator (GIGA2; Century Medical, Tokyo, Japan), and the stone was removed safely using lithotripsy (LithoCrushV; Olympus, Tokyo, Japan) ( Fig.3, Video 1), without adverse events.

Although the usefulness of the S-O clip for endoscopic retrograde cholangiopancreatography (ERCP) has been reported for normal anatomy [2], it has never been reported in DBE-ERCP. Cannulation during enteroscopy-assisted ERCP is sometimes difficult in patients with surgically altered anatomy. Various methods, including the double-guidewire technique, precutting technique, and the Rendezvous approach [3,4], have been reported. Although additional cases are needed, this safe and straightforward S-O clip-assisted cannulation could be a novel and effective method of cannulation during enteroscopy-assisted ERCP.

Endoscopy_UCTN_Code_TTT_1AR_2AG 


\section{Competing interests}

The authors declare that they have no conflict of interest.

The authors

Kotaro Takeshita, Satoshi Asai, Naoki

Fujimoto, Hitomi Jimbo, Takumi Ichinona, Eisuke Akamine

Department of Gastroenterology, Tane General Hospital, Osaka, Japan

\section{Corresponding author}

\section{Kotaro Takeshita, MD}

Department of Gastroenterology, Tane General Hospital, 1-12-21, Kujominami, Nishi-ku, Osaka, Japan 550-0025

Fax: +81-6-65812520

k.takeshita@tane.or.jp
[1] Hashimoto R, Hirasawa D, Iwaki T et al. Usefulness of the S-O clip for gastric endoscopic submucosal dissection. Surg Endosc 2018; 32: 908-914

[2] Inoue R, Kawakami H, Kubota Y et al. Endoscopic biliary intervention using traction devices for periampullary diverticulum. Intern Med 2019; 58: 2797-2801

[3] Ito K, Horaguchi J, Fujita $\mathrm{N}$ et al. Clinical usefulness of double-guidewire technique for difficult biliary cannulation in endoscopic retrograde cholangiopancreatography. Dig Endosc 2014; 26: 442-449

[4] Ishii K, Itoi T, Tonozuka R et al. Balloon enteroscopy-assisted ERCP in patients with Roux-en-Y gastrectomy and intact papillae (with videos). Gastrointest Endosc 2016; 83: 377-386
Bibliography

Endoscopy 2021; 53: E372-E373

DOI 10.1055/a-1294-9218

ISSN 0013-726X

published online 26.11.2020

(c) 2020. Thieme. All rights reserved.

Georg Thieme Verlag KG, Rüdigerstraße 14,

70469 Stuttgart, Germany

\section{ENDOSCOPY E-VIDEOS}

https://eref.thieme.de/e-videos

回的回 Endoscopy E-Videos is a free access online section, reporting 口. on interesting cases and new techniques in gastroenterological endoscopy. All papers include a high quality video and all contributions are freely accessible online.

This section has its own submission website at

https://mc.manuscriptcentral.com/e-videos 